\title{
Palaeoneurology and palaeobiology of the dinocephalian therapsid Anteosaurus magnificus
}

Julien Benoit, Ashley Kruger, Sifelani Jirah, Vincent Fernandez, and Bruce S. Rubidge Acta Palaeontologica Polonica 66 (1), 2021: 29-39 doi:https://doi.org/10.4202/app.00800.2020

Dinocephalians (Therapsida), some of the earliest amniotes to have evolved large body size, include the carnivorous Anteosauria and mostly herbivorous Tapinocephalia. Whilst the palaeoneurology of the Tapinocephalia has been investigated in Moschognathus whaitsi, that of the Anteosauria remains completely unknown. Here we used X-ray micro-Computed Tomography to study, for the first time, the palaeoneurology of Anteosaurus magnificus. Compared to Moschognathus, we reconstruct Anteosaurus as an agile terrestrial predator based on the enlarged fossa for the floccular lobe of the cerebellum and semicircular canals of the inner ear. A major difference between the two genera resides in the orientation of the braincase, as indicated by the angle between the long axis of the skull and the plane of the lateral semicircular canal. This angle is $25^{\circ}$ in Anteosaurus, whereas it is $65^{\circ}$ in Moschognathus, which suggests that the braincase of the latter was remodelled as an adaptation to head-butting. This is consistent with less cranial pachyostosis and the retention of a large canine in Anteosauria, which suggests that dentition may have been used for intraspecific fighting and display in addition to trophic interactions. The evolution of a thick skull, horns, and bosses in tapinocephalids parallels the evolutionary reduction of the canine, which lead to a shift of the agonistic function from the mouth to the skull roof, as observed in extant social ungulates. Similarly, tapinocephalians may have developed complex social behaviour.

Key words: Therapsida, Dinocephalia, head-butting, carnivory, trigeminal nerve, bony labyrinth.

Julien Benoit [julien.benoit@wits.ac.za; ORCID:

https://orcid.org/0000-0001-5378-3940], Sifelani Jirah [sifelani.jirah@wits.ac.za

; ORCID: https://orcid.org/0000-0002-6747-4388], and Bruce S. Rubidge [bruce.rubidge@wits.ac.za

; ORCID: https://orcid.org/0000-0003-2477-1873], Evolutionary Studies

Institute (ESI); School of Geosciences, University of the Witwatersrand, PO

WITS, 2050, Johannesburg, South Africa. Ashley Kruger[ashleykruger@gmail.com

; ORCID: https://orcid.org/0000-0003-1196-8693], Department of

Palaeobiology, Swedish Museum of Natural History, Post Office Box 50007,

SE-104 05 Stockholm, Sweden. Vincent Fernandez [v.fernandez@nhm.ac.uk; ORCID:

https://orcid.org/0000-0002-8315-1458], European Synchrotron Radiation Facility, 71 Avenue des 
Martyrs, 38000 Grenoble, France; Imaging and Analysis Centre, Natural History Museum, Cromwell Road, SW7 5BD, London, UK.

This is an open-access article distributed under the terms of the Creative Commons

Attribution License (for details please see creativecommons.org), which permits unrestricted use, distribution, and reproduction in any medium, provided the original author and source are credited.

Far Full text $(891.0 \mathrm{kB})$ ।

For Supplementary file $(911.3 \mathrm{kB})$ 